\title{
Subthalamic deep brain stimulation at individualized frequencies for Parkinson disease
}

E.W. Tsang, PhD

C. Hamani, MD, PhD

E. Moro, $\mathrm{MD}, \mathrm{PhD}$

F. Mazzella, RN

U. Saha, BEng

A.M. Lozano, $\mathrm{MD}, \mathrm{PhD}$,

FRCSC

M. Hodaie, MD, FRCSC

R. Chuang, MD

T. Steeves, MD

S.Y. Lim, MD

B. Neagu, MD, PhD

R. Chen, MBBChir, MSc, FRCPC

Correspondence \& reprint requests to Dr. Chen: robert.chen@uhn.ca

Editorial, page 1900

Supplemental data at www.neurology.org

Supplemental Data

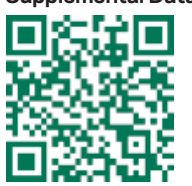

\section{ABSTRACT}

Objectives: The oscillation model of Parkinson disease (PD) states that, in the subthalamic nucleus (STN), increased $\theta(4-10 \mathrm{~Hz})$ and $\beta(11-30 \mathrm{~Hz})$ frequencies were associated with worsening whereas $\gamma$ frequencies $(31-100 \mathrm{~Hz}$ ) were associated with improvement of motor symptoms. However, the peak STN frequency in each band varied widely from subject to subject. We hypothesized that STN deep brain stimulation (DBS) at individualized $\gamma$ frequencies would improve whereas $\theta$ or $\beta$ frequencies would worsen PD motor signs.

Methods: We prospectively studied 13 patients with PD. STN local field potential (LFP) was recorded after electrode implantations, in the OFF and then in ON dopaminergic medication states while patients performed wrist movements. Six individual peak frequencies of the STN LFP power spectra were obtained: the greatest decrease in $\theta$ and $\beta$ and greatest increase in $\gamma$ frequencies in the ON state (MED) and during movements (MOVE). Eight DBS frequencies were applied including 6 MED and MOVE frequencies, high frequency (HF) used for chronic stimulation, and no stimulation. The patients were assessed using the motor Unified Parkinson's Disease Rating Scale (mUPDRS).

Results: STN DBS at $\gamma$ frequencies (MED and MOVE) and HF significantly improved mUPDRS scores compared to no stimulation and both $\gamma$ frequencies were not different from HF. DBS at $\theta$ and $\beta$ frequencies did not worsen mUPDRS scores compared to no stimulation.

Conclusion: Short-term administration of STN DBS at peak dopamine-dependent or movementrelated $\gamma$ frequencies were as effective as HF for reducing parkinsonian motor signs but DBS at $\theta$ and $\beta$ frequencies did not worsen PD motor signs.

Classification of evidence: This study provides Class III evidence that STN DBS at patient-specific $\gamma$ frequencies and at usual high frequencies both improved mUPDRS scores compared to no stimulation and did not differ in effect. Neurology ${ }^{\circledR} 2012 ; 78: 1930-1938$

\section{GLOSSARY}

BG = basal ganglia; DBS = deep brain stimulation; HF = high frequency; LFP = local field potential; $\mathbf{M E D}=$ medicationdependent peak frequencies; MOVE = movement-related peak frequencies; mUPDRS = motor Unified Parkinson's Disease Rating Scale; PD = Parkinson disease; rmANOVA = repeated-measures analysis of variance; $\mathbf{S T N}$ = subthalamic nucleus; TEED = total electrical energy delivered; VT = ventral thalamus.

Bilateral high frequency (HF 130-185 Hz) deep brain stimulation (DBS) of the subthalamic nucleus (STN) is an established treatment for advanced Parkinson disease (PD). ${ }^{1}$ Studies of oscillatory activities in the basal ganglia (BG) in patients with PD suggested that parkinsonian motor symptoms may be related to excessive pathologic oscillations in the BG in the low frequencies $(<30 \mathrm{~Hz}){ }^{2,3}$ Increased $\theta(4-10 \mathrm{~Hz})$ frequencies in STN were associated with parkinsonian resting tremor. ${ }^{4}$ Moreover, excessive $\beta(11-30 \mathrm{~Hz})$ frequencies were recorded from the STN when patients with PD were withdrawn from their dopaminergic medications $(\mathrm{OFF} \text { state })^{5-7}$ and these frequencies were reduced when patients were in the on dopaminergic

From the Division of Brain Imaging \& Behaviour Systems-Neuroscience (E.W.T., F.M., U.S., B.N., R. Chen), Toronto Western Research Institute, University Health Network; Institute of Medical Science (E.W.T., A.M.L., M.H., R. Chen), University of Toronto; Edmond J. Safra Program in Parkinson's Disease (E.W.T., C.H., E.M., F.M., U.S., A.M.L., M.H., R. Chuang, T.S., S.Y.L., B.N., R. Chen), Division of Neurosurgery, Department of Surgery (C.H., A.M.L., M.H.), and Division of Neurology, Department of Medicine (E.M., R. Chuang, T.S., S.Y.L., B.N., R. Chen), University Health Network, University of Toronto, Toronto, Canada; and University of Malaysia (S.Y.L.), Kuala Lumpur, Malaysia. Study funding: Funding information is provided at the end of the article.

Go to Neurology.org for full disclosures. Disclosures deemed relevant by the authors, if any, are provided at the end of this article. 
medication states (ON state), engaged in voluntary movements, ${ }^{5,7,8}$ or received HF STN DBS. ${ }^{9,10}$

In contrast to $\beta$ frequencies, $\gamma(31-100$ $\mathrm{Hz}$ ) frequencies in STN were related to normal motor functions. Increased $\gamma$ frequencies between 60 and $80 \mathrm{~Hz}$ in STN were often observed along with improved motor performances when patients were in their ON state or were engaged in voluntary movements. ${ }^{3,6-8}$ Moreover, STN $\gamma$ activities may be related to state of arousal as they disappeared when patients became drowsy. ${ }^{7}$ Taken together, these observations led to the hypothesis that increased STN $\gamma$ frequencies may represent improved functional state of the BG and its interaction with the cortex in patients with PD. Therefore, $\gamma$ frequencies may facilitate

Table 1 Clinical details of patients studied ${ }^{\mathrm{a}}$

\begin{tabular}{|c|c|c|c|c|c|c|c|}
\hline \multirow[b]{5}{*}{ Patient } & \multirow{5}{*}{$\begin{array}{l}\text { Age, yl } \\
\text { sex/disease } \\
\text { duration, } y\end{array}$} & \multirow{5}{*}{$\begin{array}{l}\text { Medication postop, } \\
\mathrm{mg} / \mathrm{d}\end{array}$} & \multirow{5}{*}{$\begin{array}{l}\text { Predominant symptoms } \\
\text { preoperatively }\end{array}$} & \multirow[b]{5}{*}{ Clinical DBS settings } & \multirow{5}{*}{$\begin{array}{l}\text { Preop }^{\mathrm{b}} \\
\text { MED, } \\
\text { OFF/ON }\end{array}$} & \multicolumn{2}{|l|}{ Postop, ${ }^{b}\left(\mathrm{mo}^{c}\right)$} \\
\hline & & & & & & \multicolumn{2}{|c|}{ MED } \\
\hline & & & & & & OFF & ON \\
\hline & & & & & & \multicolumn{2}{|c|}{ DBS } \\
\hline & & & & & & OFF/ON & OFF/ON \\
\hline 1 & $67 / M / 24$ & $\begin{array}{l}\text { Levodopa } 800 \text {, pergolide } \\
1 \text {, selegiline } 10\end{array}$ & $\begin{array}{l}\text { Bilateral dyskinesia, right side } \\
\text { rigidity, and bradykinesia }\end{array}$ & $\begin{array}{l}\text { LSTN } 3.6 \mathrm{~V}, 130 \mathrm{~Hz}, 60 \mu \mathrm{s}, \\
2-, 1+; \text { R STN } 3.4 \mathrm{~V} \text {, } \\
130 \mathrm{~Hz}, 60 \mu \mathrm{s}, 2-\text {, case }+\end{array}$ & $31.5 / 13$ & 29.5/18.5 & $16.5 / 13.5(5)$ \\
\hline 3 & $67 / F / 18$ & $\begin{array}{l}\text { Levodopa } 400 \text {, } \\
\text { ropinirole } 8\end{array}$ & $\begin{array}{l}\text { Freezing of gait, disabling } \\
\text { dyskinesia }\end{array}$ & $\begin{array}{l}\text { L STN } 2.6 \mathrm{~V}, 130 \mathrm{~Hz}, 60 \mu \mathrm{s}, \\
2-\text {, case+; R STN 2 V, } \\
130 \mathrm{~Hz}, 60 \mu \mathrm{s}, 2-\text {, case }+\end{array}$ & $51.5 / 22$ & $30 / 23(5)$ & 28.5/18 (22) \\
\hline 4 & $66 / M / 8$ & $\begin{array}{l}\text { Levodopa } 100, \\
\text { rotigotine } 13.5\end{array}$ & $\begin{array}{l}\text { Tremor: more severe on the } \\
\text { right side }\end{array}$ & $\begin{array}{l}\text { LSTN } 3 \mathrm{~V}, 130 \mathrm{~Hz}, 60 \mu \mathrm{s}, \\
2-, \text { case }+ \text {; R STN } 2.7 \mathrm{~V}, \\
130 \mathrm{~Hz}, 60 \mu \mathrm{s}, 2-\text {, case }+\end{array}$ & $33 / 14$ & $29.5 / 17$ & $14 / 10(2.5)$ \\
\hline 6 & $54 / \mathrm{M} / 15$ & $\begin{array}{l}\text { Levodopa } 300 \text {, } \\
\text { ropinirole } 6 \text {, selegiline } \\
2.5\end{array}$ & $\begin{array}{l}\text { Bilateral tremor, motor } \\
\text { fluctuations, dyskinesia }\end{array}$ & $\begin{array}{l}\text { LSTN } 3.8 \mathrm{~V}, 185 \mathrm{~Hz}, 60 \mu \mathrm{s}, \\
2-\text {, case }+ \text {; R STN } 4.2 \mathrm{~V}, \\
185 \mathrm{~Hz}, 60 \mu \mathrm{s}, 2-\text {, case }+\end{array}$ & $39 / 4.5$ & $35 / 7.5$ & $8 / 8(10)$ \\
\hline 7 & $63 / \mathrm{M} / 11$ & Levodopa 450 & Right side tremor, wearing off & $\begin{array}{l}\text { L STN } 3 \text { V, } 130 \mathrm{~Hz}, 60 \mu \mathrm{s}, \\
1-\text {, case }+ \text {; R STN } 2.2 \mathrm{~V}, \\
130 \mathrm{~Hz}, 60 \mu \mathrm{s}, 2-\text {, case }+\end{array}$ & $42 / 17$ & $44 / 18.5$ & $17.5 / 14(6)$ \\
\hline $8^{d}$ & $58 / \mathrm{M} / 15$ & Levodopa 1,200 & $\begin{array}{l}\text { Disabling dyskinesia, muscle } \\
\text { cramps, off period gait } \\
\text { impairment }\end{array}$ & $\begin{array}{l}\text { L STN } 3.6 \mathrm{~V}, 130 \mathrm{~Hz}, 60 \mu \mathrm{s}, \\
2-\text {, case }+ \text {; R STN } 3.4 \mathrm{~V}, \\
130 \mathrm{~Hz}, 60 \mu \mathrm{s}, 2-\text {, case }+\end{array}$ & $32.5 / 24$ & $37 / 35$ & 23/22 (7) \\
\hline 9 & $56 / \mathrm{M} / 17$ & $\begin{array}{l}\text { Levodopa } 600 \text {, levodopa } \\
\text { CR } 600 \text {, ropinirole } 6 \text {, } \\
\text { amantadine } 100\end{array}$ & $\begin{array}{l}\text { Wearing off dyskinesia, off } \\
\text { period dystonia and freezing, } \\
\text { bradykinesia }\end{array}$ & $\begin{array}{l}\text { L STN } 2.1 \mathrm{~V}, 130 \mathrm{~Hz}, 60 \mu \mathrm{s}, \\
2-\text {, case+; R STN } 2.7 \mathrm{~V}, \\
130 \mathrm{~Hz}, 60 \mu \mathrm{s}, 3-\text {, case }+\end{array}$ & $48 / 20.5$ & $42 / 18.5$ & $14.5 / 9.5(2)$ \\
\hline 13 & $44 / \mathrm{M} / 16$ & $\begin{array}{l}\text { Levodopa } 600 \\
\text { amantadine } 300\end{array}$ & $\begin{array}{l}\text { Disabling motor fluctuations } \\
\text { and severe dyskinesia }\end{array}$ & $\begin{array}{l}\text { L STN } 3.6 \mathrm{~V}, 130 \mathrm{~Hz}, 60 \mu \mathrm{s} \text {, } \\
2-\text {, case }+ \text {; R STN } 3.3 \mathrm{~V}, \\
130 \mathrm{~Hz}, 60 \mu \mathrm{s}, 3-\text {, case }+\end{array}$ & $52.5 / 18.5$ & $48.5 / 32$ & $21 / 16.5(7)$ \\
\hline
\end{tabular}

Abbreviations: $\mathrm{CR}=$ controlled release; DBS = deep brain stimulation; MED = medication-dependent peak frequencies; $\mathrm{mUPDRS}=$ motor section of the Unified Parkinson's Disease Rating Scale; STN = subthalamic nucleus.

a Patients' ages were recorded when they received DBS surgeries. Medications and clinical DBS settings were collected when patients were administered levodopa challenge and postoperative mUPDRS. Levodopa was administered with a peripheral dopa-decarboxylase inhibitor.

${ }^{b}$ Preop/Postop $=$ mUPDRS before/after DBS surgeries.

c Number of months after DBS surgeries when levodopa challenge and postoperative mUPDRS was administrated.

d Patients excluded from data analysis in experiment 2 due to incomplete data in experiment 1. 
motor performance during voluntary movements. ${ }^{3,7,8,11}$ However, the peak $\theta, \beta$, or $\gamma$ frequencies were highly variable from patient to patient. ${ }^{3,12}$

Several studies reported that levodopainduced reduction in $\beta$ band power in the STN was associated with improvements in bradykinesia and rigidity but not tremor in patients with PD. ${ }^{13-15}$ STN DBS at $20 \mathrm{~Hz}$ was found to modestly decrease tapping speeds $s^{16,17}$ but had no effect on motor symptoms ${ }^{18}$ whereas at $50 \mathrm{~Hz}$ was reported to reduce rigidity and improve tapping speed in a study with 3 subjects ${ }^{19}$ but other studies showed no benefit. ${ }^{17,18,20,21}$ No previous study examined the effects of DBS at individualized STN peak frequencies, which may be highly relevant to behavioral performances. ${ }^{10,14}$ In the present study, we examined the effects of DBS at individualized peak STN frequencies on parkinsonian motor signs. We hypothesized that STN DBS at individualized $\gamma$ frequencies would improve whereas at $\theta$ and $\beta$ frequencies would worsen PD motor signs compared to no stimulation.

METHODS Patients and surgery. We studied 13 patients with advanced PD ( 11 men, mean \pm SD age $60 \pm 6$ years, disease duration $15 \pm 4$ years) who received implantations of bilateral STN DBS electrodes (table 1).

Standard protocol approvals and patient consent. All patients provided written informed consent and the study was approved by the University Health Network Research Ethics Board.

Experiment 1: recording of STN LFP and individualized frequencies. Recordings and study protocol. STN local field potentials (LFP) recording was performed 1-3 days after electrode implantations when the leads were externalized. Patients were first studied in the practically defined OFF state after overnight withdrawal of dopaminergic medications $\mathrm{s}^{22}$ and the study was repeated in the $\mathrm{ON}$ state. The $\mathrm{ON}$ dopaminergic medication state was defined as at least 30 minutes after intake of the first morning dose of dopaminergic medications and after both the patient and experimenters noted clinical improvements. Bilateral STN LFPs were recorded from all 4 DBS contacts using linked-ear references. EMG was recorded from the extensor and flexor carpi radialis muscles to monitor wrist movements.

While sitting in a comfortable armchair, baseline STN LFP recordings were obtained for $\sim 3$ minutes. The patient then performed 2 movement tasks with their clinically more affected side (table 2). In the externally triggered task, the patient made a brisk wrist extension movement in response to a randomized visual cue appearing every 6 to 10 seconds. In the self-initiated task, the patient made self-initiated brisk wrist extension movements approximately once every 10 seconds. Each movement task lasted $\sim 10-15$ minutes.
Data analysis for experiment 1. DBS recordings were transformed into bipolar montage with the adjacent contacts $(0-1,1-2,2-3)$ to obtain focal activities. The contact pair used to obtain individualized frequencies in the $\theta, \beta$, and $\gamma$ bands was chosen to have one contact the same as the monopolar contact used for chronic DBS (table 1) for the clinically more affected side (table 2) based on subsequent programming. The adjacent contact was chosen based on the biggest changes between MED or MOVE conditions. We compared the resting power spectra between OFF and $\mathrm{ON}$ states to obtain dopaminergic medication-dependent peak frequencies (MED) (figure 1A) and between premovement and movement periods for movementrelated peak frequencies (MOVE) (figure 1B). Six individualized peak frequencies in $\theta(4-10 \mathrm{~Hz}), \beta(11-30 \mathrm{~Hz})$, and $\gamma(31-100$ $\mathrm{Hz}$ ) bands were obtained for each patient using the contacts for chronic STN DBS contralateral to the clinically more affected side (table 1). Individualized $\theta$ and $\beta$ frequencies are defined as greatest reductions in $\theta$ and $\beta$ bands in ON compared to OFF states (MED) and during movement compared to premovement periods (MOVE). Individualized $\gamma$ frequencies are defined as greatest increases in $\gamma$ band in ON compared to OFF states (MED) and during movement compared to premovement periods (MOVE). Movement-related (MOVE) frequencies were obtained from either the externally triggered or self-initiated movements in the OFF or ON states. The condition with the greatest movementrelated power change was used for each patient.

Experiment 2: testing individualized frequencies on PD motor signs. Patients who participated in experiment 1 were studied at least 3 months after surgeries to avoid microlesion effects (table 2) and allow for establishment of optimal stimulation parameters for clinical benefits (table 1)..$^{20,21}$

Each patient was tested on 2 separate days in random order: 1 day after overnight medication withdrawal and the other day while taking usual doses of medications. The testing for each day took 4 to 5 hours. Only the clinically more affected side was studied. On each day, 8 DBS frequencies were studied including 6 individualized $\theta, \beta$, and $\gamma$ frequencies in MED and MOVE conditions, stimulator turned off, and HF used for chronic DBS at the time of the experiment (table 2). The 6 individualized frequencies obtained from each patient were rounded to the closest programmable frequencies for the implanted pulse generator (table 2). The most effective monopolar (patients 2-13) and bipolar contacts (patient 1) for chronic DBS established during stimulator programming (table 1) and pulse width of $60 \mu \mathrm{s}$ was used. Because resetting the oscillation of a population of neurons is most effective with a strong pulse, ${ }^{23}$ the voltages used for all individualized frequencies were adjusted to the highest amplitudes without any side effects whereas the voltages for the HF were those used for chronic DBS. The order of DBS frequencies tested was randomized for each day of the study. Each DBS frequency was applied for 15 minutes ${ }^{18,20}$ with the other side turned off, followed by assessment of the more affected side using motor Unified Parkinson's Disease Rating Scale (mUPDRS) (items $18-31$ ) by a live rater, blinded to DBS frequencies but not to medication states. The patient then performed the handtapping test. Once the hand-tapping test was completed, the DBS was switched to another frequency. All mUPDRS assessments were videotaped and the video segments were arranged in random sequences for 2 video raters, blinded to both frequencies and medication states. The video raters independently assessed the motor signs using mUPDRS although rigidity (item 22) was not rated. See appendix e-1 on the Neurology ${ }^{\circledR}$ Web site at www.neurology.org for further details of the Methods. 


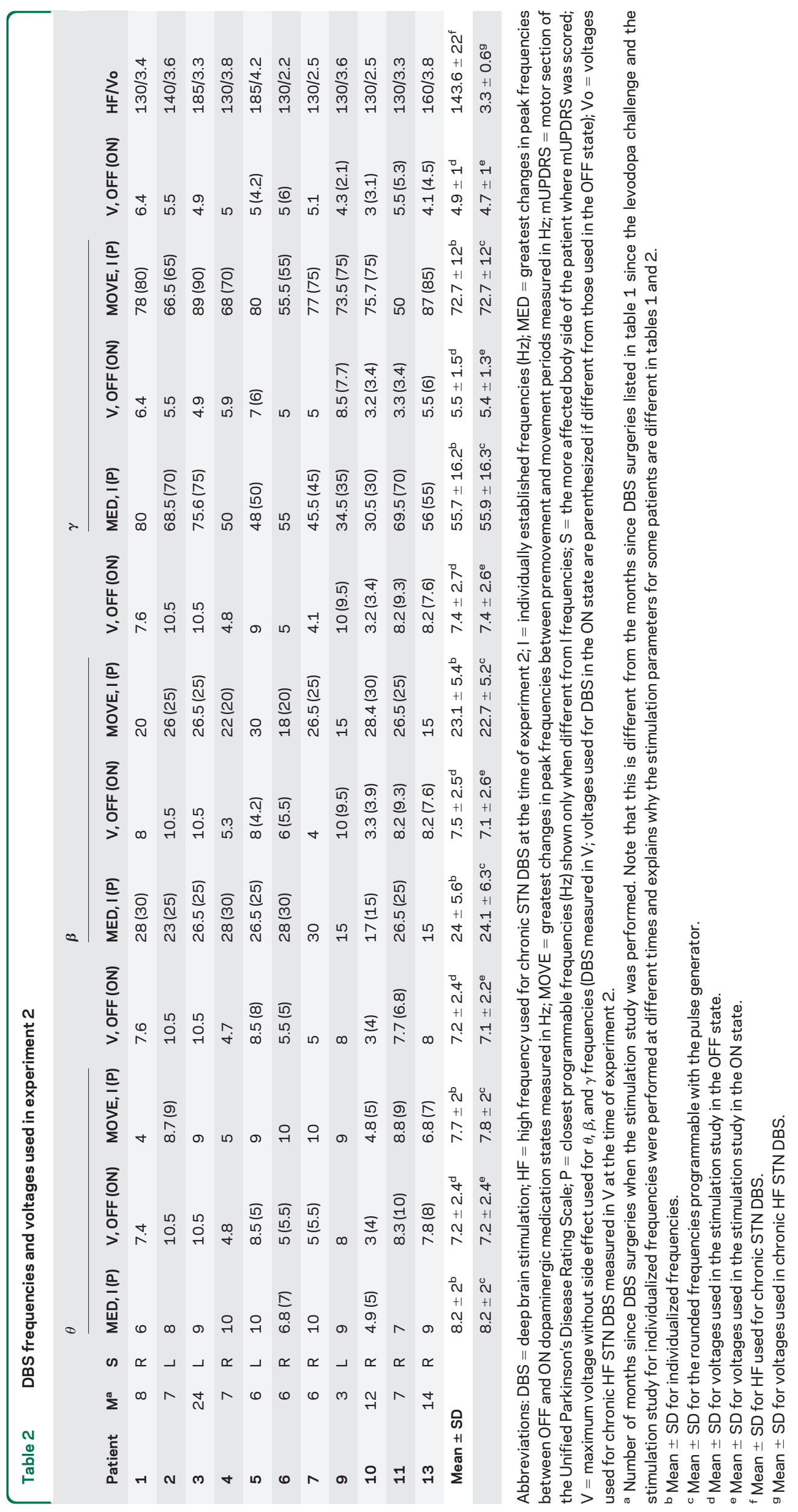


Figure 1 Examples of dopamine-dependent and movement-related power spectra of the subthalamic nucleus (STN)
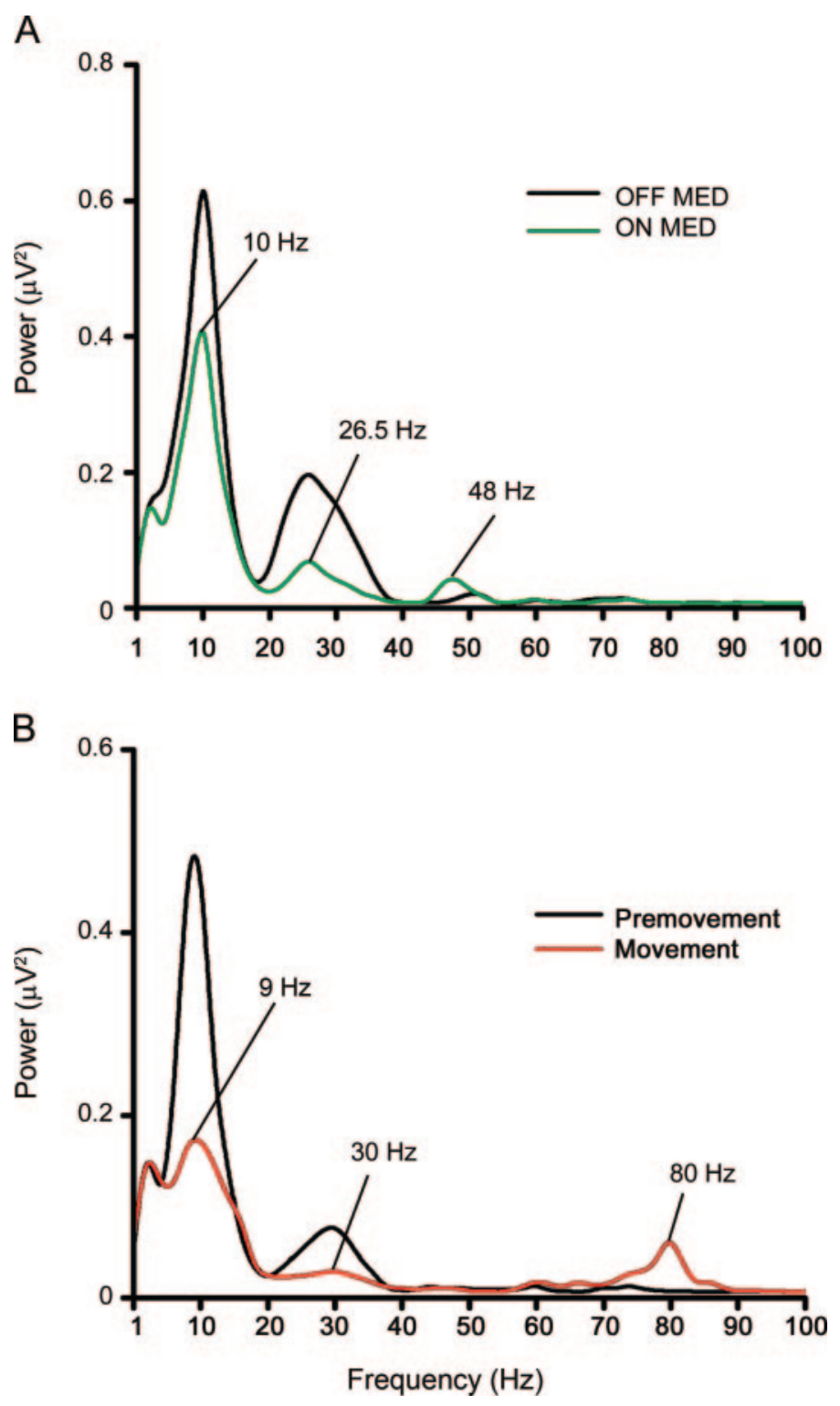

Data were recorded from right STN of patient 5. Power spectra were derived from deep brain stimulation (DBS) electrode contact pair 2-3. (A) Resting frequency spectra between 1 and $100 \mathrm{~Hz}$ in the OFF and ON dopaminergic medication states. Individualized dopaminedependent frequencies for this patient were $10 \mathrm{~Hz}$ for the $\theta$ band which showed the greatest reduction in spectral power between 4 and $10 \mathrm{~Hz}$ in the ON compared to OFF states, $26.5 \mathrm{~Hz}$ for the $\beta$ band which was the frequency with greatest reduction between 11 and $30 \mathrm{~Hz}$ in the ON compared to OFF states, and $48 \mathrm{~Hz}$ for the $\gamma$ band which showed the greatest increase between 31 and $100 \mathrm{~Hz}$ in the ON compared to OFF states. (B) Movement-related spectra between 1 and $100 \mathrm{~Hz}$ in the premovement ( -4 to $-3.5 \mathrm{~s}$ ) and the movement execution ( 0 to $0.5 \mathrm{~s}$ ) periods from an average of 79 trials of self-initiated wrist movements in the $\mathrm{ON}$ dopaminergic medication state. Individualized movementrelated frequencies for this patient were $9 \mathrm{~Hz}$ for the $\theta$ band which showed the greatest reduction between 4 and $10 \mathrm{~Hz}$ in the movement compared to premovement periods, $30 \mathrm{~Hz}$ for the $\beta$ band which showed the greatest reduction between 11 and $30 \mathrm{~Hz}$ in the movement compared to premovement periods, and $80 \mathrm{~Hz}$ for the $\gamma$ band which showed the greatest increase between 31 and $100 \mathrm{~Hz}$ in the movement compared to premovement periods.

Statistical analyses. A hemibody and axial score, representing parkinsonian motor sign of the more affected side and the trunk, was calculated for each DBS frequency by summing all subscores of mUPDRS recorded by the live and video raters. A tapping rate per 20 seconds was calculated for each DBS frequency by averaging the number of taps between the 2 runs.

For each DBS frequency, we estimated total electrical energy delivered (TEED) using the following formula: TEED = voltage $^{2} \times$ pulse width $\times$ frequency/impedance..$^{24}$ All statistics analyses were performed using SPSS v 16 (Chicago, IL). See appendix e-1 for further details on data analysis.

RESULTS Patients 8 and 12 had no change in dopamine-dependent $\gamma$ (MED) frequencies and were excluded from statistical analyses. Data from 11 patients were analyzed. Paired $t$ tests showed no significant difference between the individualized and the rounded programmable frequencies in all frequencies and the voltages used between OFF and ON states (table 2). See appendix e-1 for the results regarding variations of individualized frequencies.

Effects of DBS frequencies on PD motor signs. For the live rater, repeated-measures analysis of variance (rmANOVA) found main effects of medication states $\left(F_{I}=11.6, p=0.007\right)$ and DBS frequencies $\left(F_{7}=5.6, p=0.0001\right)$ on hemibody and axial scores (figure $2 \mathrm{~A}$ ). There was also significant interaction between medication states and frequencies $\left(F_{1,7}=2.4, p=0.03\right)$. Hemibody and axial scores were lower in the ON (mean $=15.7)$ than OFF $($ mean $=20.2)$ states. For DBS frequencies, post hoc paired $t$ tests showed that hemibody and axial scores for individualized $\gamma$ MED (mean $=14.9$ ) and MOVE (mean $=14.5$ ) frequencies and HF $($ mean $=13.8)$ were significantly lower than no stimulation (mean $=20.1)$. When the OFF and ON states were analyzed separately, post hoc paired $t$ tests indicated that DBS at individualized $\gamma$ MED (OFF: 17.5, ON: 12.4) and MOVE (OFF: 16.4, ON: 12.7) frequencies and HF (OFF: 13.7, ON: 13.9) had significantly lower hemibody and axial scores than no stimulation (OFF: 23.1, ON: 17.1) (figure 2A).

For the video raters, rmANOVA for hemibody and axial scores without rigidity showed significant main effects of medication states $\left(F_{1}=5.3, p=\right.$ $0.04)$ and DBS frequencies $\left(F_{7}=3.1, p=0.006\right)$ but the effect of rater was not significant (figure 2B). Hemibody and axial scores were lower in the ON $($ mean $=19.2)$ than OFF $($ mean $=20.8)$ states. For DBS frequencies, post hoc paired $t$ tests found that hemibody and axial scores for individualized $\gamma$ MED $($ mean $=18.7)$ and MOVE $($ mean $=18.4)$ frequencies and HF (mean $=17.9$ ) were lower than no stimulation $($ mean $=21.3)$ (figure $2 \mathrm{~B})$. There was no significant interaction between medication states and DBS frequencies.

Effects of DBS frequencies on tapping speed. For the number of taps per 20 seconds, rmANOVA found main effects in medication states $\left(F_{1}=10.8, p=\right.$ 
Figure 2 The effects of deep brain stimulation (DBS) frequencies and medication states on hemibody and axial motor Unified Parkinson's Disease Rating Scale (mUPDRS) scores

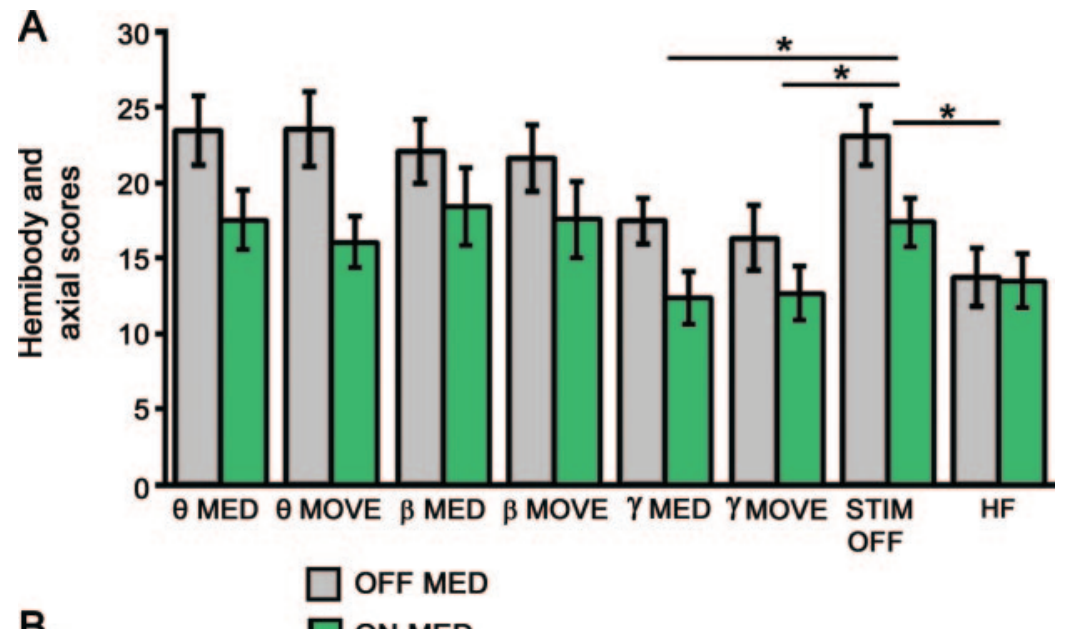

B

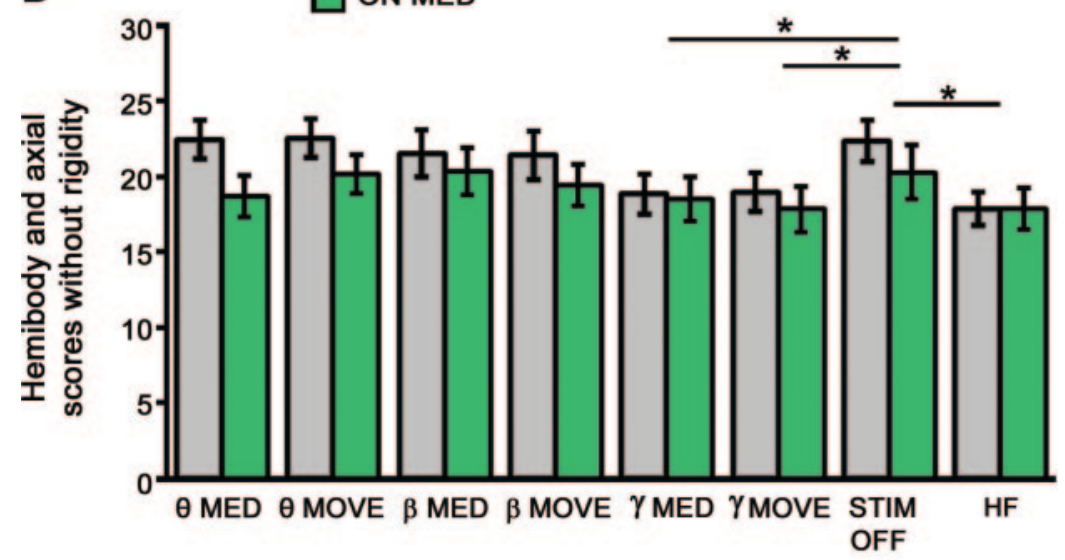

Stimulation frequencies

(A) Hemibody and axial mUPDRS scores for 8 DBS frequencies in the OFF and ON dopaminergic medication states rated by the live rater. (B) Averaged hemibody and axial mUPDRS scores without rigidity for 8 DBS frequencies in the OFF and ON dopaminergic medication states rated by the video raters. The black bars represent mUPDRS scores obtained in the OFF dopaminergic medication state while the green bars represent the ON dopaminergic medication states. $\mathrm{HF}=$ high frequencies used for chronic STN DBS; MED = individualized dopamine-dependent frequencies; MOVE = individualized movement-related frequencies; STIM OFF $=$ subthalamic nucleus DBS turned off. ${ }^{*} p<0.05$. Error bar indicates 1 SEM.

$0.008)$ and DBS frequencies $\left(F_{7}=2.27, p=0.039\right)$ (figure 3). There was no significant interaction between medication states and DBS frequencies. The number of taps per 20 seconds was higher in the ON (mean = 17.4) than OFF (mean $=16.1)$ states. For DBS frequencies, post hoc paired $t$ tests indicated that DBS at HF (mean $=18$ ) had a higher number of taps per 20 seconds than those of DBS at dopamine-dependent and movement-related $\theta$ (MED: 16.6, MOVE: 16 ) and $\beta$ frequencies (MED: 16.2, MOVE: 16.3) (figure 3). There was no significant difference in the number of taps per 20 seconds among other DBS frequencies.

DBS frequencies and electrical energy delivered. rmANOVA showed a main effect in DBS frequencies $\left(F_{7}=19.4, p=0.0001\right)$ but not medication states. Post hoc paired $t$ tests indicated that TEED for $\mathrm{HF}$ and individualized $\gamma$ frequencies were higher than those for individualized $\theta$ (MED and MOVE) frequencies ( $p=0.0003)$. Moreover, individualized $\beta$ frequencies had higher TEED than those of $\theta$ (MED and MOVE) frequencies $(p=0.002)$. There was no significant difference in TEED between individualized $\gamma$ frequencies and HF (figure e-1).

DISCUSSION In the present study, we recorded LFP from STN DBS electrodes from patients with PD and examined the effects of STN DBS at individualized dopamine-dependent and movement-related peak frequencies on parkinsonian motor signs. The results from the blinded live and the video raters showed that STN DBS at individualized dopaminedependent and movement-related $\gamma$ frequencies improved motor signs similar to HF. Although there was no significant difference in TEED for individualized $\beta, \gamma$ frequencies and HF (figure e-1), their clinical effects were different. Individualized $\gamma$ frequencies and HF reduced mUPDRS scores compared to no stimulation but individualized $\beta$ frequencies had no effect (figure 2). Therefore, improvement in mUPDRS scores may be more dependent on DBS frequencies than TEED.

The increased $\gamma$ oscillations in the BG as patients with PD transitioned from OFF to ON dopaminergic medication states were considered prokinetic because this was associated with concurrent improvements in parkinsonian motor symptoms. ${ }^{6,7}$ These dopamine-dependent $\gamma$ rhythms may also be an indicator of the arousal state as they disappeared in the BG during drowsiness ${ }^{7}$ and ceased to be observed in the ventral thalamus (VT) during deep sleep. ${ }^{25}$ In the ON state, these dopamine-dependent $\gamma$ rhythms occurred throughout the BG-thalamo-cortical network as coherences were reported to be observed between the STN, GPi, VT, and the cortex. ${ }^{7,25,26}$ These $\gamma$ rhythms were suggested to be involved in attentional processes in the BG-thalamo-cortical circuit and cortico-cortical interactions to facilitate cognition and motor-related functions. ${ }^{7,25,27}$ We demonstrated for the first time the acute clinical benefits of these intrinsic $\gamma$ frequencies of the BG through STN DBS, which decreased parkinsonian motor signs similar to that produced by well-established HF DBS. Therefore, increased $\gamma$ frequency in the STN induced by dopaminergic medications is likely a prokinetic rhythm in the human BG.

The increased $\gamma$ oscillations in the cortico-BG circuit that occurred shortly prior to and during voluntary movements in patients with PD were thought to represent the coding and the transmission of motor information between the cortico-BG network and 
Figure 3 The effects of deep brain stimulation (DBS) frequencies on tapping speed

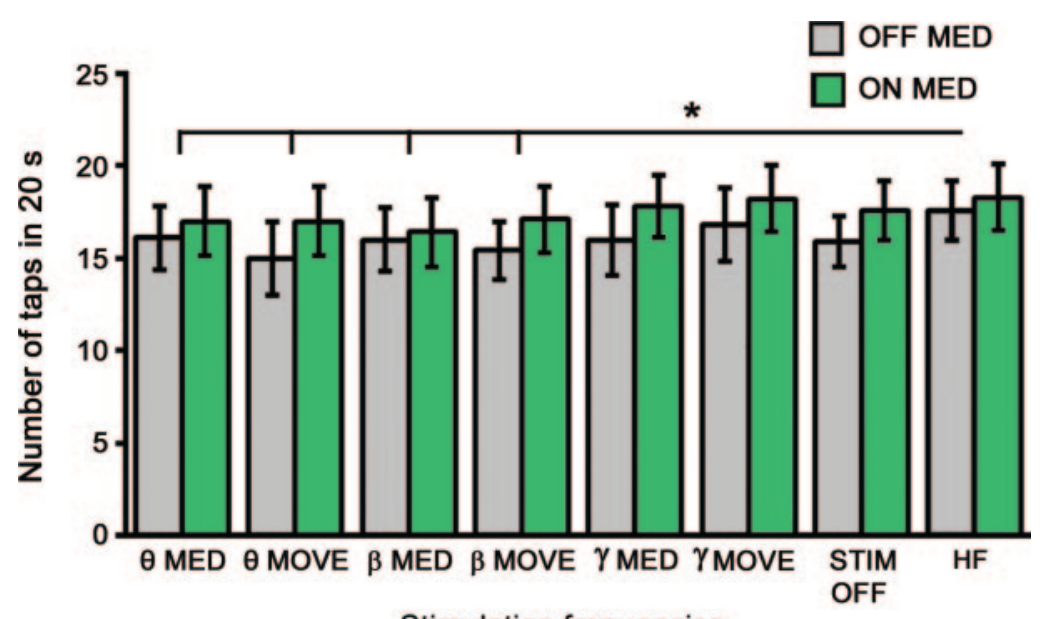

Stimulation frequencies

The black bars represent motor Unified Parkinson's Disease Rating Scale scores obtained in the OFF dopaminergic medication state while the green bars represent the ON dopaminergic medication states. $\mathrm{HF}=$ high frequencies used for chronic DBS; MED = individualized dopamine-dependent frequencies; $\mathrm{MOVE}=$ individualized movement-related frequencies; STIM OFF = subthalamic nucleus DBS turned off. ${ }^{*} p<0.05$. Error bar indicates 1 SEM.

the muscles during movement executions. ${ }^{3,28}$ These $\gamma$ frequencies were considered to represent normal movement-related activities because similar activities were recorded the GPi in dystonia patients ${ }^{29}$ and in the motor cortical regions of normal subjects or in patients with epilepsy during voluntary movements. ${ }^{30,31}$ However, the precise functions of these movement-related $\gamma$ oscillations in the cortico-BG circuit remains unclear. Our results indicated that peak $\gamma$ frequencies in the STN during voluntary movements were effective in decreasing parkinsonian motor signs, consistent with the hypothesis that these $\gamma$ oscillations may reflect outputs of the BG-thalamocortical network representing coding of voluntary movements and promotion of these $\gamma$ oscillations may thus facilitate movement executions.

Dopamine-dependent $\gamma$ oscillations in the BG have been suggested to be a carrier rhythm mediating information transfer between the BG and the motor cortical areas during voluntary movements. HF stimulation, empirically effective frequencies for chronic STN DBS, was hypothesized to be the second harmonics of intrinsic BG dopamine-dependent or movement-related $\gamma$ rhythms and therefore effective in reducing PD motor signs. ${ }^{7}$ Our results indicated that although similar peak frequencies in the $\gamma$ range were found in 3 patients (patients 1, 2, 6) (table 2), most patients displayed distinct $\gamma$ peak frequencies in dopamine-dependent and movement-related conditions. Moreover, HF for chronic STN DBS (table 2) was not the second harmonics of the specific dopamine-dependent or movement-related $\gamma$ peak frequencies we found in the STN. Another hypothesis regarding the therapeutic effects of HF STN DBS involved the disruption of abnormal rhythms in the BG network, in particular the $\beta$ frequencies. ${ }^{2,9,10}$ Whether DBS at peak $\gamma$ frequencies also suppress excessive $\beta$ oscillations in the BG needs to be examined. These results suggest that the BG-cortical circuit may have 2 prokinetic $\gamma$ rhythms with peak frequencies that are variable across patients and they may be effective in reducing parkinsonian motor symptoms.

Previous studies using STN DBS in the $\gamma$ range at $\sim 50 \mathrm{~Hz}$ did not produce consistent clinical benefit and at least $100 \mathrm{~Hz}$ is required to produce consistent reductions in parkinsonian motor signs..$^{18,20,21}$ These are in contrast to our findings that dopaminedependent or movement-related peak $\gamma$ frequencies in the STN between 30 and $90 \mathrm{~Hz}$ were as effective as $\mathrm{HF}$ in reducing PD motor signs (figure 2, figure e-2). The reason for this difference may be because $\gamma$ frequency DBS need to be at the intrinsic peak frequency to be effective and the optimal $\gamma$ frequency varied widely among patients (table 2). ${ }^{3,12}$ In the present study, we used the individual peak STN $\gamma$ frequencies rather than setting the DBS at a fixed $\gamma$ frequency. However, we need to study $\gamma$ frequencies other than the individualized peak $\gamma$ frequencies to determine whether the prokinetic effects are specific to individualized peak $\gamma$ frequencies. The effects of STN DBS at individualized dopamine-dependent and movement-related peak $\gamma$ frequencies warrant further investigations to optimize chronic DBS treatments for PD.

Our results showed that applying dopaminedependent or movement-related peak $\theta$ or $\beta$ frequencies of the STN did not increase PD motor signs whether in the OFF or ON states as measured by mUPDRS. Previous studies of STN DBS at $\theta$ and $\beta$ frequencies did not produce consistent results. Unilateral STN DBS at $5 \mathrm{~Hz}$ was found to reduce hand-tapping speed. ${ }^{20}$ Two studies that measured finger-tapping rate with the repetitive depression of a single key with the index finger found that bilateral STN DBS at 5 and $20 \mathrm{~Hz}$ reduced tapping speed by $\sim 12 \%$ and $\sim 8 \%$ compared with no stimulation but only a subgroup of patients with PD who demonstrated normal baseline tapping rate and stimulation at $10 \mathrm{~Hz}$ did not decrease tapping rate compared to no stimulation. ${ }^{16,17}$ In contrast, bilateral STN DBS at $10 \mathrm{~Hz}$ was found to significantly worsen PD motor symptoms particularly bradykinesia measured by mUPDRS but stimulation at 5 and $20 \mathrm{~Hz}$ had no effect. ${ }^{18}$ We found that STN DBS at individualized peak $\theta$ or $\beta$ frequencies did not slow hand-tapping 
speed compared to no stimulation. This may be because we used different methods compared to previous studies. Our hand-tapping test involved more complex arm movements compared to the simple finger tapping. ${ }^{16,17} \mathrm{We}$ used peak $\theta$ or $\beta$ STN frequencies instead of fixed frequencies and used unilateral STN DBS instead of bilateral stimulations used in previous studies. ${ }^{16-18}$ Regardless of differences in methodologies and findings, STN DBS at $\theta$ and $\beta$ frequencies did not produce a consistent increase in parkinsonian motor symptoms. No previous study examined the effect of low-frequency STN DBS in the ON medication state. Our results suggest that STN DBS at peak $\theta$ and $\beta$ frequencies did not block the effects of levodopa (figure 2). Therefore, increased $\theta$ or $\beta$ oscillations in the STN may be indicators $^{13-15,32}$ rather than contributors to PD motor symptoms. However, we cannot rule out subtle effects. It is also possible that the single pulse stimulations we used were not sufficient to synchronize the intrinsic $\theta$ and $\beta$ rhythms. A train of pulses may be required $^{33}$ but this type of setting was not possible with the pulse generator used. See appendix e- 1 for a discussion of the limitations of the study.

Short-term STN DBS at individualized peak oscillations of dopamine-dependent and movementrelated $\gamma$ frequencies are as effective as conventional $\mathrm{HF}$ for reducing parkinsonian motor signs. The long-term effects of individualized $\gamma$ frequency STN DBS need to be examined in future studies.

\section{AUTHOR CONTRIBUTIONS}

Dr. E.W. Tsang: data collection, analysis and interpretation, drafting and revising the manuscript. Dr. C. Hamani: data collection and analysis, manuscript revision. Dr. E. Moro: conceptualization of the study, data collection, manuscript revision. F. Mazzella: data collection, manuscript revision. U. Saha: data collection, manuscript revision. Dr. A.M. Lozano: data collection, manuscript revision. Dr. Mojgan Hodaie: data collection, manuscript revision. Dr. R. Chuang: data collection, manuscript revision. Dr. T. Steeves: data collection, manuscript revision. Dr. S. Lim: data collection, manuscript revision. Dr. B. Neagu: data analysis, manuscript revision. Dr. R. Chen: conceptualization of the study, data interpretation, manuscript revision.

\section{STUDY FUNDING}

Supported by the Michael J. Fox Foundation for Parkinson Research and the Canadian Institutes of Health Research (CIHR, grant number MOP15128). Eric W. Tsang was supported by a CIHR Canada Graduate Scholarship Doctoral Award. Andres Lozano is supported by Canada Research Chair in Neurosciences. Robert Chen is supported by a CIHRIndustry (Medtronic Inc.) Partnered Investigator Award and the Catherine Manson Chair in Movement Disorders.

\section{DISCLOSURE}

Dr. Tsang reports no disclosures relevant to the manuscript. Dr. Hamani receives honoraria for travel and speaking from Medtronic and St. Jude Medical and serves as a consultant for St. Jude Medical. Dr. Moro received honoraria for serving on the educational advisory board for Medtronic. She was a consultant for and received honoraria for lecturing from Medtronic, and received research support from St. Jude Medical. Ms. Mazzella, Mr. Saha, Dr. Chuang, Dr. Steeves, and Dr. Neagu report no disclosures. Dr. Lozano received honoraria and research grant from Medtronic Inc and St. Jude Medical. He serves as consultants for Medtronic, St Jude Medical, Boston Scientific, Amgen, Ely Lilly, Bristol, Myers, Elekta, Bayer, Schering-Plough, QIG, and Functional Neuroscience. Dr. Hodaie received speaker honoraria and research grant from Medtronic Inc. and received research support from St. Jude Medical. Dr. Lim reports no disclosures relevant to the manuscript. Dr. R. Chen received consulting fees from Medtronic Inc. He is supported by a CIHRIndustry (Medtronic Inc.) Partnered Investigator Award (ISI 83213). Go to Neurology.org for full disclosures.

Received July 17, 2011. Accepted in final form November 4, 2011.

\section{REFERENCES}

1. Benabid AL, Chabardes S, Mitrofanis J, Pollak P. Deep brain stimulation of the subthalamic nucleus for the treatment of Parkinson's disease. Lancet Neurol 2009;8: $67-81$.

2. Hammond C, Bergman H, Brown P. Pathological synchronization in Parkinson's disease: networks, models and treatments. Trends Neurosci 2007;30:357-364.

3. Brown P. Oscillatory nature of human basal ganglia activity: relationship to the pathophysiology of Parkinson's disease. Mov Disord 2003;18:357-363.

4. Reck C, Florin E, Wojtecki L, et al. Characterisation of tremor-associated local field potentials in the subthalamic nucleus in Parkinson's disease. Eur J Neurosci 2009;29: 599-612.

5. Levy R, Ashby P, Hutchison WD, Lang AE, Lozano AM, Dostrovsky JO. Dependence of subthalamic nucleus oscillations on movement and dopamine in Parkinson's disease. Brain 2002;125:1196-1209.

6. Alonso-Frech F, Zamarbide I, Alegre M, et al. Slow oscillatory activity and levodopa-induced dyskinesias in Parkinson's disease. Brain 2006;129:1748-1757.

7. Brown P, Oliviero A, Mazzone P, Insola A, Tonali P, Di Lazzaro V. Dopamine dependency of oscillations between subthalamic nucleus and pallidum in Parkinson's disease. J Neurosci 2001;21:1033-1038.

8. Androulidakis AG, Kuhn AA, Chen CC, et al. Dopaminergic therapy promotes lateralized motor activity in the subthalamic area in Parkinson's disease. Brain 2007;130: 457-468.

9. Kuhn AA, Kempf F, Brucke C, et al. High-frequency stimulation of the subthalamic nucleus suppresses oscillatory beta activity in patients with Parkinson's disease in parallel with improvement in motor performance. J Neurosci 2008;28:6165-6173.

10. Bronte-Stewart H, Barberini C, Koop MM, Hill BC, Henderson JM, Wingeier B. The STN beta-band profile in Parkinson's disease is stationary and shows prolonged attenuation after deep brain stimulation. Exp Neurol 2009; 215:20-28.

11. Brown P, Williams D. Basal ganglia local field potential activity: character and functional significance in the human. Clin Neurophysiol 2005;116:2510-2519.

12. de Solages C, Hill BC, Koop MM, Henderson JM, Bronte-Stewart H. Bilateral symmetry and coherence of subthalamic nuclei beta band activity in Parkinson's disease. Exp Neurol 2010;221:260-266.

13. Ray NJ, Jenkinson N, Wang S, et al. Local field potential beta activity in the subthalamic nucleus of patients with Parkinson's disease is associated with improvements in bradykinesia after dopamine and deep brain stimulation. Exp Neurol 2008;213:108-113. 
14. Kuhn AA, Tsui A, Aziz T, et al. Pathological synchronisation in the subthalamic nucleus of patients with Parkinson's disease relates to both bradykinesia and rigidity. Exp Neurol 2009;215:380-387.

15. Weinberger M, Mahant N, Hutchison WD, et al. Beta oscillatory activity in the subthalamic nucleus and its relation to dopaminergic response in Parkinson's disease. J Neurophysiol 2006;96:3248-3256.

16. Eusebio A, Chen CC, Lu CS, et al. Effects of lowfrequency stimulation of the subthalamic nucleus on movement in Parkinson's disease. Exp Neurol 2008;209: 125-130.

17. Chen CC, Litvak V, Gilbertson T, et al. Excessive synchronization of basal ganglia neurons at $20 \mathrm{~Hz}$ slows movement in Parkinson's disease. Exp Neurol 2007;205:214221.

18. Timmermann L, Wojtecki L, Gross J, et al. Ten-Hertz stimulation of subthalamic nucleus deteriorates motor symptoms in Parkinson's disease. Mov Disord 2004;19: $1328-1333$.

19. Limousin P, Pollak P, Benazzouz A, et al. Effect of parkinsonian signs and symptoms of bilateral subthalamic nucleus stimulation. Lancet 1995;345:91-95.

20. Moro E, Esselink RJ, Xie J, Hommel M, Benabid AL, Pollak P. The impact on Parkinson's disease of electrical parameter settings in STN stimulation. Neurology 2002; 59:706-713

21. Rizzone M, Lanotte $M$, Bergamasco B, et al. Deep brain stimulation of the subthalamic nucleus in Parkinson's disease: effects of variation in stimulation parameters. J Neurol Neurosurg Psychiatry 2001;71:215-219.

22. Langston JW, Widner H, Goetz CG, et al. Core assessment program for intracerebral transplantations (CAPIT). Mov Disord 1992;7:2-13.

23. Tass PA, Klosterkotter J, Schneider F, Lenartz D, Koulousakis A, Sturm V. Obsessive-compulsive disorder: develop- ment of demand-controlled deep brain stimulation with methods from stochastic phase resetting. Neuropsychopharmacology 2003;28(suppl 1):S27-S34.

24. Moro E, Lang AE, Strafella AP, et al. Calculating total electrical energy delivered by deep brain stimulation systems. Ann Neurol 2005;58:168-169.

25. Kempf F, Brucke C, Salih F, et al. Gamma activity and reactivity in human thalamic local field potentials. Eur J Neurosci 2009;29:943-953.

26. Williams D, Tijssen M, Van Bruggen G, et al. Dopaminedependent changes in the functional connectivity between basal ganglia and cerebral cortex in humans. Brain 2002; 125:1558-1569.

27. Brown P, Marsden CD. What do the basal ganglia do? Lancet 1998;351:1801-1804.

28. Cassidy M, Mazzone P, Oliviero A, et al. Movementrelated changes in synchronization in the human basal ganglia. Brain 2002;125:1235-1246.

29. Tsang EW, Hamani C, Moro E, et al. Movement-related potentials and oscillatory activities in the human internal globus pallidus during voluntary movements. J Neurol Neurosurg Psychiatry 2012;83:91-97.

30. Ball T, Demandt E, Mutschler I, et al. Movement related activity in the high gamma range of the human EEG. Neuroimage 2008;41:302-310

31. Cheyne D, Bells S, Ferrari P, Gaetz W, Bostan AC. Selfpaced movements induce high-frequency gamma oscillations in primary motor cortex. Neuroimage 2008;42:332342 .

32. Zaidel A, Spivak A, Grieb B, Bergman H, Israel Z. Subthalamic span of beta oscillations predicts deep brain stimulation efficacy for patients with Parkinson's disease. Brain 2010;133:2007-2021.

33. Hahn PJ, Russo GS, Hashimoto T, et al. Pallidal burst activity during therapeutic deep brain stimulation. Exp Neurol 2008;211:243-251.

\section{$\longrightarrow$ \\ Editor's Note to Authors and Readers: Levels of Evidence in Neurology ${ }^{\circledR}$ \\ Effective January 15, 2009, authors submitting Articles or Clinical/Scientific Notes to Neurology ${ }^{\circledR}$ that report on clinical therapeutic studies must state the study type, the primary research ques- tion(s), and the classification of level of evidence assigned to each question based on the AAN classification scheme requirements. While the authors will initially assign a level of evidence, the final level will be adjudicated by an independent team prior to publication. Ultimately, these levels can be translated into classes of recommendations for clinical care. For more information, please access the articles and the editorial on the use of classification of levels of evidence published in Neurology. ${ }^{1-3}$ \\ 1. French J, Gronseth G. Lost in a jungle of evidence: we need a compass. Neurology 2008;71:1634-1638. \\ 2. Gronseth G, French J. Practice parameters and technology assessments: what they are, what they are not, and why you should care. Neurology 2008;71:1639-1643. \\ 3. Gross RA, Johnston KC. Levels of evidence: taking Neurology ${ }^{\circledR}$ to the next level. Neurology 2009;72:8-10.}

